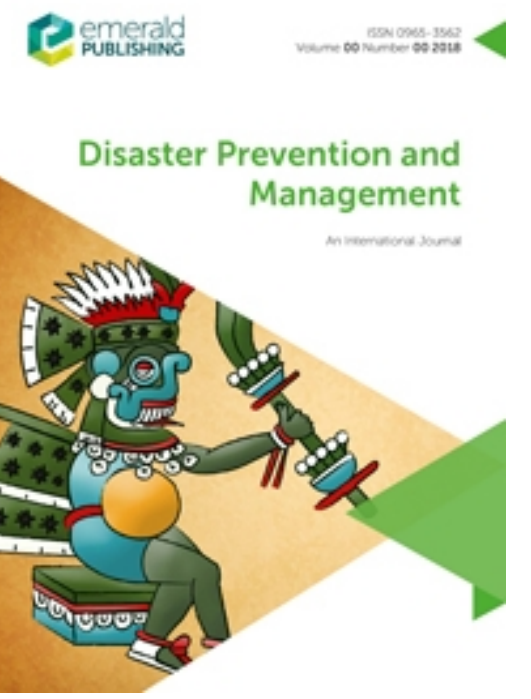

\title{
Testing the precautionary argument after the Lucky Dragon incident
}

\begin{tabular}{|r|l|}
\hline Journal: & Disaster Prevention and Management \\
\hline Manuscript ID & DPM-01-2020-0020.R1 \\
\hline Manuscript Type: & Research Paper \\
\hline Keyword: & $\begin{array}{l}\text { Climate Change, Nuclear Crisis, Uncertainty Theory, Japanese History, } \\
\text { C.-N. Martin, U.S. Weather Bureau, Thermonuclear bombs }\end{array}$ \\
\hline \multicolumn{2}{|l}{} \\
\hline
\end{tabular}

\section{SCHOLARONE \\ Manuscripts}




\section{Testing the precautionary argument after the Lucky Dragon incident Research paper}

Abstract

\section{Purpose}

This paper uses a historical case study, the controversy over the possibility of climatic extremes caused by hydrogen bomb tests on Pacific Ocean atolls during the 1950s, to show how in a context of few scientific data and high uncertainty, political affiliations and public concerns shaped two types of argumentation, the 'energy and the 'precautionary' arguments.

\section{Design/methodology/approach}

Systematic analysis of publications 1954-1956: scientific and semi-scientific articles, publications C.-N. Martin; and contemporary newspaper articles, especially from the AsiaPacific region.

\section{Findings}

First, epistemological and scientific reasoning about the likelihood of extreme natural events aligned to political convictions and pressure. Second, a geographical and social distribution of arguments: the relativizing 'energy argument' prevailed in English-language scientific journals, while the 'precautionary argument' dominated in popular journals and newspapers published worldwide. Third, while the 'energy argument' attained general scientific consensus within two years, it lost out in the long run. The proponents of the 'precautionary argument' raised relevant research questions that, though first rejected in the 1950s, later exposed the fallacies of the 'energy argument' (shown for the case of the climatologist William W. Kellogg).

\section{Originality/value}

In contrast with the existing secondary literature, this paper presents a balanced view of the weaknesses and strengths of two lines of arguments in the 1950s. Further, this historical study sheds light on how once-discarded scientific theories may ultimately be reconsidered in a completely different political and scientific context thus justifying the original precautionary argument.

\section{Keywords}




\section{Climate change, Nuclear Crisis, Uncertainty Theory, Japanese History, C.-N. Martin, U.S. Weather Bureau, Thermonuclear bombs}

This paper presents a historical case study, the controversy over the possibility of climatic extremes caused by hydrogen bomb tests on Pacific Ocean atolls during the 1950s. In March and April, 1954, a series of six atmospheric H-bomb tests caused an environmental and political crisis unprecedented in scale, and led Japanese meteorologists to explore a possible link between these explosions and the following, abnormally cold, summer in Northern Japan. The meteorologists' concern followed a worldwide public outcry over the irradiation of the native population and Japanese fishermen in the Fukuryu Maro (Lucky Dragon) incident, in which the size and direction of the radioactive cloud significantly exceeded expectations. In Japan, the fishing industry suffered heavy losses, and now, in addition, there was also concern over bad harvests of rice crops due to climatic changes.

The attribution of bad weather to the Pacific H-bomb explosions led to public and scientific controversy about whether concern about weather and long-term climate changes was grounded in good scientific reasons or were just another expression of irrational fear and general ignorance. This paper argues that there were two opposite ways of interpreting this controversial issue. One side tended to relativize the size of thermonuclear bombs, by belittling their effects in comparison with the energies involved in winds and storms on Earth. This will be called here the 'energy argument.' The other side stressed the uniqueness of this sudden, extreme and unprecedented human intervention on Earth, and pointed to the possibility of long-term and yet unknown consequences for the Earth's environment. This will be called here the 'precautionary argument,' with reference to the 1992 UN definition of the precautionary approach: "Where there are threats of serious or irreversible damage, lack of full scientific certainty shall not be used as a reason for postponing cost-effective measures to prevent environmental degradation" (United Nations, 1992).

Following this historical controversy is instructive: First, it shows how epistemological and scientific reasoning aligned with political convictions. The arguments put forward displayed the political forces and interests behind them: the physical argument served to defend the testing and the bomb, while the precautionary argument served to contest them. Most Western politicians regarded nuclear tests as absolutely necessary to perfect weapons and defend freedom against communism. For them, leading American and British 
meteorologists provided welcome arguments to continue the tests. On the opposing side, there was an increasingly worried worldwide public, physically affected by the tests, ranging from the irradiated native population in the vicinity, to the entire Asian-Pacific region, and ultimately to the whole world. Second, there was a geographical and social distribution of these arguments: the physical argument reigned in leading English-speaking scientific journals, official statements, and governmental hearings in the United States and Britain, while the precautionary argument was brought forward predominantly in popular journal articles, books, and letters, published all over the world. Third, while the energy argument carried the day within two years, it lost out in the long run. With scientific hindsight from a few decades later, mere energetic calculations could no longer do justice to the complexity of the world's climate. This study shows how scientific arguments to judge the likelihood of natural extremes are tied to specific contemporary conditions, and also explains why the precautionary argumentation could not get any traction at the time.

Recent historical studies, by repeating without further analysis the condescending statements of the leading American and British meteorological experts, have tacitly accepted the experts' claims about the irrationality and naiveté of the public's attitude and the shallowness of alternative scientific and semi-scientific interpretations (Higuchi, 2011) (Hamblin, 2013). The most thorough investigation of the Japanese reaction, based on extensive archival research and an analysis of Japanese newspapers, was carried out by Toshihiro Higuchi (Higuchi, 2011) (Higuchi, 2008). He contrasts the general panic in Japan with the sober expert analysis of the U.S. Weather Bureau meteorologists. For Higuchi, the public fears about weather - contrary to fears of radiation - appear unjustified and irrational. This paper objects to this interpretation. First, Higuchi did not analyze the scientific arguments on both sides of the debate. He thus dismisses a priori as irrelevant any reasoning other than the U.S. Weather Bureau's. Furthermore, he did not look at the broader spectrum of actors. Those who considered possible climatic consequences of the tests in 1954/1955 included a number of scientists, among them several Nobel Prize winners and politicians. Finally, Higuchi misses another important point: he does not take into account that the very U.S. meteorologists in charge of investigating the consequences of the explosions were those who actively participated in and attended the tests. At the height of the Cold War information was kept under a tight lid; U.S. meteorologists were not able to communicate everything they knew, and had to adjust to political pressure. All this left those scientists and meteorologists who were outside this tight circle little choice other than to remain silent or to work with approximate data and many uncertainties, and to distrust what was said-or not said-in official 
statements. The alternative scientific statements and publications that advanced the 'precautionary argument' thus reflected the constraints of the time and resulted from the specific political situation of the Cold War. This paper presents a more balanced representation of the weaknesses and strengths of two lines of argumentation. In addition to scientific and semi-scientific publications, it will analyze newspaper articles, especially from the Asian-Pacific region, during the years 1954 to 1956, as well as the publications by the French physicist Charles-Noël Martin that were widely discussed at the time but have not been analyzed in the existing secondary literature.

\section{The 'precautionary argument'}

The precautionary argument was advanced in the countries directly affected by Pacific nuclear tests of 1954. For the Japanese public, the Lucky Dragon incident and the irradiation of fishermen in March 1954 added another trauma after Hiroshima and Nagasaki, leading to a "nationwide panic in Japan" about radioactive tuna (Higuchi, 2008, p. 335). In the following months, Japanese meteorologists pointed to yet another possible danger: the explosions might also cause reduced temperatures due to dust lifted into the stratosphere. They drew an analogy to the 1883 explosive eruption of Krakatau, in today's Indonesia, whose dust had diminished solar radiation, causing a cold summer (Yoshinobu and Fujita, 1954) (Arakawa, 1954). Given this possibility, and facing a situation of high uncertainty due to the absence of information on the explosions, they opted for precautionary action and an appeal for a ban on weapons of mass destruction. Concerned by a rising number of atmospheric nuclear tests by the United States, Soviet Union and Great Britain, the Japanese Meteorological Society joined a rapidly rising number of appeals in Japan and elsewhere (Wittner, 1997) and declared at their annual meeting:

"We are convinced that our duty as scientists is to join forces with all who strive for peace and demand with emphasis and courage the stopping of further hydrogen tests and the banning of all kinds of atomic weapons in the name of saving humanity." (South China Morning Post, 9 July 1954)

Their appeal came during the coldest summer of the last 25 years, and a long rainy season, which further reinforced the general panic and aversion to the tests. The meteorologist, Hidetoshi Arakawa of the Japanese Meteorological Research Institute, referred to the "fear ... 
shared by many people here in Japan," that the "abominable experiments" could cause weather anomalies (Arakawa, 1954, p. 125). Based on data from six representative Japanese weather stations between 1883 and 1954, Arakawa showed that bad harvests resulted from cooler summers. During the unusually cool and rainy summer of 1954, Arakawa had observed a slight decrease in solar radiation, which he attributed to the dust in the high atmosphere due to the nuclear explosions. He admitted the limitations of his research and that the nuclear explosions might not have been "the unique cause of the bad harvests." (Arakawa, 1954, p. 132).

The Japanese worries about climate change echoed throughout the world. Similar concerns had already been expressed in the United States, in connection with nuclear tests in Nevada. Now, given the heightened alarm over global atmospheric irradiation, the topic of climatic change also gripped a worldwide audience. European, American and Asian newspapers contained letters from worried readers, who reported about unusual weather phenomena (Brien, 2014) (Higuchi, 2011). Nobel prize winners criticized the tests, and, responding to the considerable worldwide attention, the World Meteorological Organization (WMO) also decided to investigate the issue, in September, 1954 (WMO Bulletin, 1954). However, the WMO, with the powerful director of the U.S. Weather Bureau Francis Reichelderfer as its president, refused to appeal for a stop to the tests, as it has been requested by the Japanese delegation with support from the Soviet Union (Higuchi, 2011, p. 96). American and British influence within this institution blocked this precautionary initiative.

The debate intensified in November 1954, when the physicist and Nobel Prize winner Louis de Broglie presented to the French Académie des Sciences a short text from the young physicist Charles-Noël Martin (1923-2005) (Martin, 1954). Martin had worked with the nuclear physicist and Nobel Prize winner Irène Joliot-Curie. He was the first qualified scientist who, with the approval of the prestigious French institution, went public and sketched out possible consequences of nuclear tests. Martin pointed to "especially severe if not dramatic consequences" of the thermonuclear explosions which corresponded to 1000 to 2500 Hiroshima bombs: chemical (production of nitric acid (NO) and modification of the acidity of rain), climatic (due to the dust in the stratosphere and a reduction of solar radiation, also leading to increased rain), radioactive (production of numerous isotopes, especially Carbon-14), and genetic (with irreversible effects) (Martin, 1954, p. 1288). He concluded with an implicit formulation of the precautionary argument, disguised as warning against scientific hubris: A rising number of nuclear explosions may have non-linear consequences which may lead to a "rising disequilibrium of the natural conditions" and an irreversible 
situation (Martin, 1954, p. 1289). Given the complexity of the issue, pure theory may fail as it had also in the case of the Lucky Dragon incident.

Martin's speculative ideas were widely debated in the following months. Capitalizing on the enormous worldwide attention, Martin swiftly wrote a popular book, entitled L'Heure H a-t-elle sonné pour le monde? Effets accumulatifs des explosions nucléaires, which provided a more elaborate defense of the precautionary argument and a valuable introduction to nuclear weapons and their physical effects. Martin was worried about the long-term effects of the nuclear tests, due to radiation and its effects on human beings, animals and plants, and to changes to the atmosphere and the climate of the Earth. The book assembled the scientific information available, relying on official American reports and scientific articles as well as Japanese sources and observations made all over the world. As was obvious from the attention-grabbing title, it was not a scientific publication, but a work of scientific popularization, an effort to provide as much as possible reliable information for a large audience. At the same time, it was a highly political book, as Martin made a strong scientific case against the nuclear weapons tests, listing possible long-term disturbances, ranging from the dust in the atmosphere, changing $\mathrm{pH}$ of rain to the catalytic reactions of chemical substances produced by the nuclear explosion. Stressing the rudimentary understanding of the complex system of the atmosphere, he now advanced the precautionary argument in explicit terms: "It is better to do exaggerated forecasts and to understand afterwards that they were fortunately overestimated than to do the inverse." (Martin 1955, p. 158).

In an introduction to the book, Albert Einstein supported Martin's precautionary approach, pleading scientists to not submit themselves to the demand of secrecy, the "slavery of the nationalistic state." Einstein compared the modern scientist to "a soldier, who sacrificed his own life." (Martin, 1955, p. 13) He feared that the superpowers' leading scientists' silence reinforced the general feeling of uncertainty and disinformation. Given the uncertainties on a theoretical level, he said, the nuclear tests should not be carried out. Einstein was not alone in his concerns; other Nobel prize winners expressed similar fears, for example, the atmospheric scientist Victor Hess (Brien, 2014), who was strongly opposed to the testing. Hess feared its severe environmental consequences, and advanced the precautionary argument: "We know too little." (New York Times, 1964). Finally, in July 1955, the Russell-Einstein Manifesto warned of the dangers of a nuclear war and appealed for peaceful solutions to settle conflicts, though not explicitly asking for an immediate moratorium on nuclear tests.

\section{The 'energy argument'}


The 'energy argument' had already been around since the first A-bombs, in discussion about their potential to divert hurricanes (Brien, 2014). However, it became a standard argumentation only in the early 1950s due to strong public and political pressure to provide a definitive statement that nuclear weapon tests would not affect the weather and the climate. In the context of the Cold War the American government considered the tests to be indispensable and asked American meteorologists to go public to reassure a worried public. A nervous American public and many newspaper articles blamed a rise in hurricanes and tornados on the nuclear tests in Nevada of the early 1950s. Numerous letters and complaints had been addressed to the U.S. Weather Bureau and the AEC (Atomic Energy Commission). It fell to the U.S. Weather Bureau and its chief meteorologist, Harry Wexler, to deal with them. Wexler initiated a two-year study, led by the two meteorologists from the U.S. Weather Bureau, Lester Machta and D. L. Harris, subsequently published in Science. Machta had inside knowledge about the atmospheric effects of nuclear explosions, as he headed a secret special project section within the U.S. Weather bureau, created in 1946, which was to provide expertise in detecting Soviet nuclear explosions, to study air circulation in the lower and upper atmosphere, and to forecast weather and to do fall-out projections for nuclear weapon tests. Machta had also personally attended nuclear tests in Nevada and the Pacific.

The U.S. Weather Bureau made sure to include meteorologists all over the United States. Machta and Harris first asked them to send in their observations and possible interpretations of weather and climate changes. From about 80 responses, they ultimately selected only three possible mechanisms: "atomic debris might serve as cloud-seeding agent," "changes in the electric parameters of the atmosphere" and "interference with solar radiation." All three were physical mechanisms. The report considered them to be insignificant and concluded that there was "no reason for believing that any past atomic explosion at the Nevada Proving Ground has had any significant effect on the weather more than a few miles away from the test site." (Machta and Harris, 1955, p. 75) If there had apparently been more tornados in the year of 1953, this was due to better collection of tornado statistics, the authors argued. In support of their findings they invoked the 'physical argument': "The thermal energy from the sun falling on $1 \mathrm{~m}^{2}$ of Nevada ground during an average spring day supplies as much heat as two nominal bombs." (Machta and Harris, 1955, p. 78).

Machta and Harris regarded any effect on climate as unlikely. For Higuchi, their “negative conclusion" was "carefully qualified" (Higuchi, 2011, p. 97). However, while the article weighed the available evidence, data, and opinions of meteorologists, it is significant 
that it made no mention of the many unknowns in the nascent field of atmospheric and climatic studies. The Science article also did not examine the recent Pacific H-bomb tests of 1954, which were on a completely different scale by a factor of 1000 in comparison to the Abombs. The authors mentioned a lack of "sufficient data" as reason (Machta and Harris, 1955, p. 80), but most likely they had no permission to use the existing data. By not considering the H-bomb explosions, the article did little to calm Japanese fears. The Japanese government and the U.S. embassy in Tokyo were eager for an authoritative American scientific evaluation to calm a worried public in order to avoid unrest, anti-American resentment and political disruption in Japan (Higuchi, 2008, p. 338).

The Science article also served for the hearings before the Joint Committee on Atomic Energy on April 1955, which were meant to address American concerns over public safety in the aftermath of nuclear testing. Present at the hearings alongside Harry Wexler and Lester Machta was the physicist John von Neumann, who had recently been elected a member of the Atomic Energy Commission. Von Neumann dismissed any concerns and invoked the "energy argument':

"The energy involved in an atomic bomb is large by ordinary concepts, but not very large from the point of energies involved in climate and meteorology. I think 1 inch of rain over the State of Pennsylvania corresponds to 2,000 megatons.” (Health and Safety, 1955, p. 35)

Von Neumann also discussed the role of dust in reducing solar heating and used the eruption of Krakatau in 1883 for comparative purposes. One Krakatau eruption over a period of ten to twenty years would bring about a new ice age. However, he expressed his belief that "the amount of material thrown up by Krakatoa was about 100 times that of the largest nuclear explosion so far." (Health and Safety, 1955, p. 36). Hence, he saw no reason to assume largescale climatic effects. Wexler confirmed Neumann's statement with data from two solar observatories that showed no reduction of solar radiation in the aftermath of the most recent thermonuclear explosions. Wexler repeated von Neumann's 'energy argument': “Even Hbombs with energies several hundred times that of the nominal A-bomb, represent less than 1/100 of 1 percent the energy of winds in the atmosphere." (Health and Safety, 1955, p. 42). He also compared pre-atomic and after-atomic weather, and saw no significant difference.

\section{The debate over public ignorance and scientific uncertainty}


From November 1954 to 1956, there was a lively debate between these two positions on many levels: in newspapers, scientific journals, and governmental hearings. Two characteristic features emerge from the debate: the struggle against public ignorance, and, second, the handling of scientific uncertainty.

Those advancing the energy argument saw themselves as defenders of reason. They dismissed public concerns as illogical, speculative, and merely associative. Harry Wexler, not without a certain aloofness, pointed to the fallacy of taking correlation for causation:

"There is a natural human tendency to associate two events occurring together as cause and effect. This holds in many fields but is particularly prevalent in weather. ... a nuclear explosion is blamed simultaneously for heavy rains or drought, cold weather or hot weather, stormy weather or lack of wind. The interesting feature of this historical process is that the variety of weather changes is equaled only by man's inventiveness in trying to explain them." (Health and Safety, 1955, p. 37).

Clearly, Wexler was frustrated that his persistent efforts to educate the public on statistics continued to fail. The issue was not going away. Even in 1958 large parts of the population in many states believed that atom bombs changed the weather (Spiegel, 1958). Many continued to trust their own feelings more than the statements of experts.

Miscomprehension of statistics was an easy target for claiming scientific superiority. Dealing with the scientific arguments, as advanced by the Japanese meteorologists and Charles-Noël Martin, was a different matter. A review in Nature of Martin's book by a British atmospheric researcher, N.G. Stewart, who worked in a military institution, gives insight into the reception of Martin's book. Stewart first summarized the precautionary argument, without engaging with it. The rest of his review was dismissive, describing the book as more or less scientifically worthless, lacking in data, and doing "no estimate in the real sense." The author also pointed to "several errors of fact," without specifying them. Finally, the last part of his review ridiculed Martin, by associating him with a belief in "flying saucers," a term which Martin had not used when speaking of atmospheric effects (Stewart, 1955, p. 1056). Ridicule also dominated in a few strongly-worded opinion articles in English-speaking newspapers which just straightforwardly dismissed Martin's argument: One author stated sarcastically that Martin had "provided amateur students of the weather with a Christmas present," (South China Morning Post, 31 Dec 1954), while another spoke of an "intensive campaign to 
generate fear," containing "not a word of truth." (The Straits Times, 1 May 1955). Nuanced statements in defense of the energy argument were published in scientific journals by British meteorologists. However, they also omitted references to recent publications by Japanese scientists or Martin, and made sure to draw a line between expert and lay persons, accusing the latter's arguments to be "merely intuitive or based on misleading analogies" (Mason, 1955, p. 141) or just "speculation (unfortunately, often ill-formed and emotional" (Sutton, 1955, p. 319).

The proponents of the precautionary argument responded to these dismissive remarks by stressing scientists' ignorance. This was mostly framed in terms of the failure of theory (e.g. South China Sunday Post, 28 March 1954). There were many unknowns and surprises. Prediction had failed in 1954: the Castle Bravo H-bomb test had exceeded scientists' calculations by more than $200 \%$; furthermore, meteorological forecasting had been wrong leading to the Lucky Dragon incident. Scientists were hiding their own doubts or ignorance behind the screen of secrecy. As Martin correctly observed, "the secrecy was broken by the explosions' own consequences," which were reported in numerous private letters from observers to family members, and also remarked indirectly, for example by the modification of photographic plates due to radioactive particles in the air (Martin, 1955, p. 13). Scientific as well as amateur observations had brought the effects of the tests into the public sphere. Martin pointed especially to the work of Japanese scientists, who had built up "a complex system of detection," measuring the radioactivity of rain and snow, atmospheric pressure changes, changing electricity in the atmosphere, and variations of the sea level at costal stations (Martin, 1955, p. 115).

Uncertainty dominated in science for Martin: "We know very little of the mechanisms of the elements that constitute our world" (Martin, 1955, p. 156). He also pointed to the multiple uncertainties around the tests themselves, and concluded that it would be best to stop them, given the fragility of the Earth. In his book, he directly criticized the 'physical argument,' which came from scientists who were involved in the tests. "The error of these eternal optimists" was to stress the "immensity of the Earth" and to consider the H-bomb as merely "a drop in the ocean." (Martin, 1955, p. 154). He pointed to the underlying assumption of this argument: given the immensity of the globe, nature would return to an equilibrium through its ongoing cycles of transformation between air, earth, and life, after a minor disturbance. Where they saw stability and continuity, despite the momentary disruption caused by thermonuclear bombs, Martin saw the danger of a permanent disequilibrium of the Earth's ecosystem. The atmosphere, Martin warned, had only the "thickness of a stamp on a 
sphere of one meter in diameter." (Martin, 1955, p. 166). "Energy does not signify anything in meteorology," Martin stated, to counter the "fallacious reasoning" of his opponents. (Martin, 1955, p. 174). For him what counted more than the immediate physical effects, were the longterm consequences of the presence of dust and chemical substances in the atmosphere, which could decrease surface temperatures on the Earth, with devastating consequences for food production.

Contrary to Wexler and von Neumann, Martin regarded meteorology as a field with many unknowns. He took atmospheric chemistry as an example: Severe human intervention had already taken place by putting $\mathrm{CO}_{2}$ into the atmosphere since industrialization. Martin stressed that the atmosphere was a complex system, hardly understood in current meteorology, and that there was a possibility that thermonuclear tests could provoke major transformations by way of catalytic reactions, so that there might no longer be a linear relation between the size of the explosion and its subsequent effects. As an example, Martin mentioned the fact that NO (nitric acid) was produced by nuclear explosions, which could react by catalysis, or by changing the $\mathrm{pH}$ value of rain. Increasing acidity would then also have severe repercussions on harvests (Martin, 1955, pp. 160-163).

Wexler did not directly address the issue of general uncertainty. He focused on available data and quantitative measurements, and drew a clear line between those hypotheses for which there were data, and those for which there were not. The former could be verified, while the latter could be verified only to a certain degree of probability:

“... there may be some hypothesis for a reasonable connection between explosions and weather for which no data are available for checking. We have examined these possibilities and have found from the standpoint of physics that they do not work. We may be wrong. However, of those particular speculations that were made and which we could test with data we found out that the data did not support them.... We assume that the speculations have been laid to rest." (Health and Safety, 1955, p. 47-48).

The quotation shows that Wexler was careful enough to include a caveat: he limited his analysis strictly to physics, leaving out atmospheric chemistry. Wexler's focus remained on what could be known, excluding the unknowns from consideration. For Wexler, the 'energy argument' was based on solid quantitative data and could therefore be verified. This left any other non-quantitative and non-physical reasoning as mere speculation and thus not worthy of serious scientific attention at that moment. Wexler's formulations left the door open for future 
research that might show his reasoning to be wrong. Wexler's narrow argumentation contrasted with a statement by the Nobel Prize winner Frederick Soddy, who stressed the general uncertainty in the field of meteorology: "It is rediculous [sic] of scientists and weather experts to deny that the atom bombs and nuclear piles affect the weather ... they do not know one way or the other ..." (Sidney, 1954)

While the American scientists avoided explicit talk about uncertainties, the British meteorologist Graham Sutton, director of the Meteorological Office addressed them directly. In his 1955 publication in Nature, he listed a whole range of uncertainties: the impossibility of saying something about weather trends before a few years had passed; lack of detailed information about the nuclear tests; and the "present uncertainty, concerning the mechanism of many fundamental atmospheric processes" that "make it impossible to give a rigorous demonstration of the truth or falsity of the proposition that thermonuclear explosions were responsible, or even contributed materially, to the poor summer of 1954 in western Europe." (Sutton, 1955, p. 319). Sutton attributed degrees of plausibility to the various factors which might have caused climate change. While remaining open to the possibility that some of his arguments might be subject to revision, he came to the conclusion that "the available evidence points to the conclusion that recent thermonuclear trials cannot be held responsible for any world-wide extremes of weather encountered in 1954." (Sutton, 1955, p. 21) His colleague, B.J. Mason of the Imperial College in London, was less nuanced. Though he also stressed "the immense complexity and variability of meteorological events and our incomplete understanding of the physical processes," and the necessity to speak in "probabilities," he nevertheless stated that "critical assessment" was possible. Mason's argumentation ultimately followed the 'energy argument,' comparing the atmosphere to a "thermodynamic engine." (Mason, 1955, p. 139).

\section{Political context and evolution of the debate}

The debate over climate modification took place at the intersection of two historic developments: on the one hand, three nuclear powers energetically pursued the construction of H-bombs, while on the other hand, the peace movement gained momentum. The arguments of the debate reflected underlying political standpoints. At the 1955 U.S. Senate hearing, the chairman of the committee set the tone: "In this grim race with the communist world our position of preeminence is vital to the security of the free world." (Health and Safety, 1955, p. 
1). His statement made clear that, while public safety was important, testing had priority. For the meteorologists of the U.S. Weather Bureau, who were government employees and had security clearance, there was no free speech, as Einstein had correctly noted in his preface to Martin's book. They argued in scientific terms, but given the multiple uncertainties and the political context, they had to boil down their reasoning to a core that could stick with politicians as well as with the public, and which could not be contested: the "energy argument.' Their statements are striking for what they left out: arguments from any discipline other than physics, and discussion, or at least a list of sources and observations, from outside the United States. Their statements were political in the sense that they made no reference to the on-going political debate, sticking solely to scientific and technical issues. Einstein and other Nobel Prize winners could freely speak their mind, and many of them joined the appeal against nuclear weapons. Martin dared to speak out, but he did himself no career favor as a physicist, and subsequently worked as a popularizer of science. In the foreword to the 1956 Japanese edition of his book, Martin regretted the fact that scientists were not able to speak out freely (Martin, 1956). The 'precautionary argument' was, in the end, only for those who were willing to take a great risk of being wrong and to go against the powerful nuclear establishments in their countries.

During 1955, the 'energy argument,' widely distributed in scientific journals and increasingly in newspapers, was increasingly accepted. Sporadically, alternative ideas about how the bombs could affect climate emerged here or there, but they rapidly vanished without much further discussion (Bengelsdorf, 1956). Given also that overall there was no strikingly unusual weather, a consensus among scientists emerged that there was no convincing scientific reason that required an immediate test ban. This consensus strengthened in the summer of 1955 on the occasion of meetings like a July conference in Paris, where the "alarmist suggestions" were refuted by French meteorologists who judged them "extremely unlikely" (Rabinowitch, 1956, p. 35) and at the occasion of the August UN conference on the Peaceful Uses of Atomic Energy, which many important players, among them Martin, attended. Rather, the focus was on how to prevent a nuclear war and the pressing issue of the radioactive pollution of the atmosphere. The 1956 report of the National Academy of Sciences (NAS) further considered any changes to weather unlikely (Committee, 1956), also confirmed by a report published in 1956 in the Soviet Union (Fedorov, 1957). In 1956 the WMO decided to shut down its investigation into weather and focus rather on radiation measurements (WMO Bulletin, 1957). The United States government had succeeded in imposing its viewpoint. Symptomatic for the sensitive political situation was also another 
corollary fact: while Martin's book was translated into thirteen languages (among them German, Spanish, Polish, and Japanese), there were no English or Russian translations. This further hampered the spread of Martin's ideas in the very countries which carried out the tests.

\section{Conclusion}

In 1987 the American physicist and meteorologist William W. Kellogg wrote an overview article in Climatic Change on "Mankind's impact on climate," in which he reflected upon the recent rise of studies on climate change. He observed:

"Only $25 \mathrm{yr}$ [sic] ago few scientists would have expressed much concern over this question. If prodded a bit, one could easily show that the total power output of all human activities (about $8 \times 10^{12} \mathrm{~W}$ ) was utterly insignificant (about $1 / 10000$ ) compared to the radiant heat absorbed from the sun. This simple argument seemed to prove that we could not influence the heat balance of the earth nor its climate, and so the matter stood. But there are always a few independent spirits who are not willing to accept obvious answers without searching for other possibilities. Can there be leverage points in the complex system that determines climate leverage points that we can reach?” (Kellogg, 1987, pp. 113-114).

Yes, he confirmed, "the human influence on global climate" was obvious when looking at the increases of carbon dioxide and greenhouse gases (Kellogg, 1987, pp. 114, 117-118).

Kellogg's remarks point to a decisive turn in the atmospheric sciences in the late 1960s and early 1970s, when atmospheric chemistry moved to the forefront of research, exemplified by Paul Crutzen's work on ozone.

Kellogg's career exemplifies the turn from the 'energy argument' to the 'precautionary argument.' As a promising young physicist at RAND he had done partly secret work on the atmospheric and climatic consequences of nuclear test explosions, trying to develop models for projecting radioactive fallout. He had also participated in the 1956 NAS report on the Committee on Meteorological Aspects of the Effects of Atomic Radiation. The quotation of 1987 above thus reflected also his own belief during the 1950s that the energy of nuclear bombs was small when compared to the energies of the sun's radiation and atmospheric circulation. Now, thirty years later, with hindsight, he had realized that the 
energy argument could fail. Research in atmospheric chemistry had provided the leverage points to disqualify this argument drawn from physics.

Martin's ideas did not have an influence on the rise of climate change studies.

Nevertheless, it is striking to see how in this field some of Martin's speculative arguments and ways of thinking have come to be discussed and been partly confirmed during the last decades. Already, the 1956 NAS report, written after the energy argument had won, went beyond the energy argument and reasoning in probability, and opened up to terms like "trigger mechanism" and "catalytic effects." Overall the report sounded slightly less optimistic, stressing the difficulties to make "a final authoritative evaluation." (Committee, 1956, p. 112). There was also the possibility that H-bombs could indeed have a large, possibly global effect on atmospheric electric conductivity, disrupting communication systems.

With time, it became ever more evident how little was known. During the 1960s, E.S. Batten, studying the possible climatic consequences of nuclear war at RAND, acknowledged uncertainty and frankly admitted that "our knowledge [of meteorological processes] is yet insufficient to provide unambiguous answers" (Batten, 1966, p. iii). Ten years later, in 1975, a review paper on "Inadvertent weather and climate modification" was probably the first to refer directly Martin's ideas on atmospheric chemistry and to discuss favorably Martin's concern over the oxidation of nitrogen and its consequences on ozone concentration. (Barrett and Landsberg, 1975, p. 39). The 1980s saw debate over the possibility of nuclear winter as a consequence of nuclear war, something that a Japanese meteorologist had already considered in the 1950s (Yoshinobu, 1954, p. 2012). The 1990s provided the ultimate confirmation that the eruption of Krakatau, which had served in the 1950s for Japanese scientists as an analogy to nuclear test explosions, had indeed modified the Earth's temperature. Finally, in the $21^{\text {st }}$ century scientists expressed concern that even a relatively limited regional atomic war (for example between India and Pakistan) may severely affect the climate of the whole Earth (Robock et al., 2019). While not all of this research was not inspired by Martin's ideas, it validated retroactively some elements of his precautionary reasoning.

What to do with this hindsight from the year 2020? Was the precautionary argument, as proposed by Japanese meteorologists and Martin, right in the end? Instead of asking whether they were right or wrong, perhaps we should frame this story differently: the 'energy' proponents erred by narrowing the issue down to the single parameter of energy; the 'precautionary' proponents erred by thinking too broadly and too speculatively. As shown above, neither line of argumentation was simply "scientific"; both depended on available data and followed political preferences and public pressure. While ultimately the nuclear tests of 
the 1950s and 1960s did not change the weather or climate in significant ways, ironically, the research topic itself, once tossed into the open, had staying power, and ultimately led to research that found new answers to old questions. In a different political and scientific context, this work sidelined the energy argument and ultimately supported the original precautionary approach.

This historical case study shows how widely accepted scientific explanations, used in the 1950s for risk management and risk communication, were overturned by subsequent scientific research in a different political and scientific environment. Fifty years later, what seemed reasonable in the 1950 s was no longer so. This study invites rethinking about how to deal with public fear and precautionary arguments advanced by those directly confronted with a potential hazard. Precautionary arguments are often semi-scientific and sometimes speculative. Nevertheless, they may contain predictive and analytic elements that may be confirmed by future scientific research. The study encourages us to take precautionary arguments seriously and to submit them speedily to thorough scientific examination.

\section{Bibliography}

Arakawa, A. et al. (1955), "Climatic Abnormalities as Related to the Explosions of Volcano and Hydrogen-bomb”, Geophysical Magazine, Vol. 26, No. 2, pp. 231-255.

Arakawa, H. (1954), "Possible Atmospheric Disturbances and Damages to the Rice-Crops in Northern Japan that may be Caused by Experimentation with Nuclear Weapons", Geophysical Magazine, Vol. 26, No. 1, pp. 125-134.

Barrett, E.W. and Landsberg H.E. (1975), "Inadvertent Weather and Climate Modification”, C R C Critical Reviews in Environmental Control, Vol. 6, No. 1, pp. 15-90. https://doi.org/10.1080/10643387509381634.

Batten, E.S. (1966), The Effects of Nuclear War on the Weather and Climate, RAND Corporation, Santa Monica, CA.

Bengelsdorf, I. (1956), “Can the atom change the weather?”, The Saturday Review, 7 July, pp. 31-34.

Brien, J.D. (2014), The Weather Is Usually Unusual: Nuclear Weapons Testing in the Age of Atmospheric Anxiety, 1945-1963 (Master thesis), University of Virginia, Charlottesville, https://doi.org/10.18130/V3J38B. 
Committee on Meteorological Aspects of the Effects of Atomic Radiation (1956), "Meteorological Aspects of Atomic Radiation", Science, Vol. 124, No. 3212, pp. 105 112.

Fedorov, E.K. (1957), “The Influence of Atomic Explosions on Meteorological Processes”, Journal of Nuclear Energy, Vol. 5, No. 1, pp. 135-45.

Hamblin, J.D. (2013), Arming Mother Nature: The Birth of Catastrophic Environmentalism, Oxford University Press, Oxford.

Health and Safety Problems and Weather Effects Associated with Atomic Explosions (1955), Hearing, Joint Committee on Atomic Energy, Congress of the United States, 15 April, Washington.

Higuchi, T. (2008), “An Environmental Origin of Antinuclear Activism in Japan, 1954-1963: The Government, the Grassroots Movement, and the Politics of Risk", Peace \& Change, Vol. 33, No. 3, pp. 333-67. https://doi.org/10.1111/j.14680130.2008.00502.x.

Higuchi, T. (2011), Radioactive fallout, the politics of risk, and the making of a global environmental crisis, 1954-1963 (Ph.D. thesis), Georgetown University, Washington.

Kellogg, W.W. (1987), "Mankind's impact on climate: The evolution of an awareness", Climatic Change, Vol. 10, No. 2, pp. 113-136.

Machta, L. and Harris D.L. (1955), "Effects of Atomic Explosions on Weather”, Science, Vol. 121, No. 3134, pp. 75-81. https://doi.org/10.1126/science.121.3134.75.

Martin, C.-N. (1954), "Sur les effets accumulatifs provoqués par les explosions thermonucléaires à la surface de la terre", Comptes-rendus de l'Académie des sciences, Vol. 239, pp. 1287-1289.

Martin, C.-N. and Mokichirō Nogami (1956), H (suiso) no gyōshō wa jinrui no tameni nattadearōka? : genshi kaku bakuhatsu no ruiseki kōka H, Oyama Shoten, Tōkyō.

Martin, C.-N. (1955), L’heure H a-t-elle sonné pour le monde? Effets accumulatifs des explosions nucléaires, Grasset, Paris.

Mason, B.J. (1955), “Atomic explosions and the weather”, Weather, No. 10, pp. 139-141.

New York Times (1964) "Victor F. Hess, Physicist, Dies. Shared the Nobel Prize in 1936”, 19 December, p. 29.

Rabinowitch, E. (1956), "International Cooperation of Atomic Scientists", Bulletin of the Atomic Scientists, Vol. 12, No. 2, pp. 34-37, 61, http://doi.org/10.1080/00963402.1956.11453683. 
Robock, A. et al. (2019), "How an India-Pakistan nuclear war could start-and have global consequences”, Bulletin of the Atomic Scientists, Vol. 75, No. 6, pp. 273-279, http://doi:10.1080/00963402.2019.1680049.

Sidney, J. (1954), “The Weather-and A-bombs”, The Singapore Free Press, 12 January.

South China Morning Post (1954), “Cold Summer. Suggested Effect of H-Bomb Tests. Japanese Theory", 9 July, p. 12.

South China Morning Post (1954), "H-Bombs and Rain”, 31 December, p. 10.

South China Sunday Post (1954), "New Precautions for H-Bomb Tests”, 28 March, p. 17.

Spiegel (1958), “Unverändert veränderlich”, Vol. 34, 20 August, pp. 38-46

Stewart, N.G. (1975), “L'heure H, a-t-elle sonné pour le monde, book review,” Nature, Vol. 175, p. 1056, http://doi.org/10.1038/1751056b0.

Sutton, G. (1955), “Thermonuclear Explosions and the Weather”, Nature, Vol. 175, No. 4451, pp. 319-321.

United Nations (1992) Rio Declaration on Environment and Development, Rio de Janeiro.

Wittner, L.S. (1997), The Struggle against the Bomb: A History of the World Nuclear Disarmament Movement, 1954-1970, Stanford University Press, Stanford.

WMO Bulletin (1954), "Notes techniques", Vol. 3, No. 4, p. 121.

Yoshinobu, M. (2012), 'From 'Black Rain' to 'Fukushima': The Urgency of Internal Exposure Studies", The Asia-Pacific Journal, Vol. 10, No. 39,3, pp. 1-7.

Yoshinobu, M. and Fujita T. (1954), “Kon’natsu no ijyō kikō to suibaku no eikyō" [This Summer's Abnormal Weather and the Influence of H-Bombs], Tenki, Vol.1, No. 4, pp. 121-124, 110. 